Canadian University Music Review

Canadian University Music Review

Revue de musique des universités canadiennes

\title{
From Composer to Audience: the Production of "Serious" Music in Canada
}

\author{
Regula Burckhardt Qureshi, Alan Lessem, John Beckwith, Alfred Fisher et \\ Barry Truax
}

Volume 9, numéro 2, 1989

URI : https://id.erudit.org/iderudit/1014908ar

DOI : https://doi.org/10.7202/1014908ar

Aller au sommaire du numéro

\section{Éditeur(s)}

Canadian University Music Society / Société de musique des universités

canadiennes

ISSN

0710-0353 (imprimé)

2291-2436 (numérique)

Découvrir la revue

Citer ce document

Burckhardt Qureshi, R., Lessem, A., Beckwith, J., Fisher, A. \& Truax, B. (1989).

From Composer to Audience: the Production of "Serious" Music in Canada.

Canadian University Music Review / Revue de musique des universités

canadiennes, 9(2), 117-137. https://doi.org/10.7202/1014908ar

All Rights Reserved ( C Canadian University Music Society / Société de musique des universités canadiennes, 1989
Ce document est protégé par la loi sur le droit d'auteur. L'utilisation des services d'Érudit (y compris la reproduction) est assujettie à sa politique d'utilisation que vous pouvez consulter en ligne.

https://apropos.erudit.org/fr/usagers/politique-dutilisation/ 


\section{COLLOQUY}

\section{FROM COMPOSER TO AUDIENCE: THE PRODUCTION OF “SERIOUS" MUSIC IN CANADA}

Regula Burckhardt Qureshi, Alan Lessem, John Beckwith, Alfred Fisher, Barry Truax

\section{Introduction}

This joint presentation originated in a Round Table Discussion which was held at the Joint Annual Meeting of AMS, CMS, SEM, and SMT in November 1985 at Vancouver. In a larger sense, it arises from one ethnomusicologist's concern with the nature and role of contemporary music making and thus forms part of the expanding dialogue between ethnomusicologists and Western music specialists.

Western art music is normally analysed in terms of its sound structure and its meaning identified in terms of its own stylistic and aesthetic parameters. This has led to the general assumption that art music is free from contextual constraints and that the concert is an enduring catalyst for this most abstract of arts, not subject to social constraints or social change. This, in turn, has resulted in a neglect of the social contextual dimension as a significant factor in the analysis of Western art music which, I believe, leaves a gap in our understanding of the role this music plays in contemporary Canadian society and of the kinds of social change it may be subject to. Such an understanding is particularly needed today, when established orchestras threaten to collapse and contemporary composers struggle for a hearing of their music.

As an ethnomusicologist whose focus has been on the process of music production elsewhere (1987), I am assuming that contemporary Canadian art music - and "serious" music generally - shares fundamental characteristics with other kinds of music, allowing one to approach it in the same way as Sufi songs or Indian ragas, that is, as 
any music created for performance today. Such an approach would extend two basic premises to the music under consideration.

First, if music is a sound message created by a music maker for a listerner, then its communication becomes actual in performance, that is, when the composer's score is made audible to an audience - not when an adjudicator reads that score. ${ }^{1}$ For "serious" music today this has become complex to the point of removing the originator of the communication - the composer - from the receiver - the listener in time and space. From this emanate charges that composers do not compose for listeners and that composers are alienated from listeners, or, conversely, that listeners are not concerned with what composers might be saying today.

Central to the nature of the contemporary music making process is the objectification of the composer's utterance, usually in the form of a score, an artifact that can be commissioned, bought, deposited and treated as a document of Canadian creativity, not to mention its study and analysis. Recordings are a further extension of this objectification of music. All this, I believe, contributes to a certain mystification (to borrow a Marxian term), of the basic reality about music making as a process that extends from a composer to an audience. It is to this process we wish to address ourselves here.

Second, an essential source for understanding the music making process are the participants, prime among them the music maker himself. This holds true, I believe, even where an investigator of his own music can rely on his expertise, for it is the dynamic between protagonist and observer that generates the potential for insightful analysis.

In Western art music practice only contemporary music allows access to living composers and therefore access to the music making process in its entirety. In order to initiate the scrutiny of this process, our present focus is directed to the first link in the chain, the composer. To begin with, musicologist Alan Lessem sets the stage with a cultural-historical perspective on the place of the composer and the forces that govern musical production in contemporary Canadian society. Then Alfred

1 Notwithstanding the famous instance of Brahms on his sofa where he could hear a better performance of Don Giovanni in his head than by going to the opera. He - and all of us whose life is enriched by such "head" music - are beneficiaries of an acute tonal memory which enables us to retain and mentally improve upon - the sound of actual performances. 
Fisher, John Beckwith, and Barry Truax each present positions that represent their particular outlook and commitment as composers, making it possible to identify issues of common conern as well as to gather together individual insights into a composite profile. This profile, we believe, represents a valid point of departure for an evaluation of the composer's vantage point and role within the music making process.

\section{Alan Lessem}

In relation to audiences, the composer of today is the child of an historical development which has its roots in the early 19th century and which becomes more pervasive as time goes on. I am referring, namely, to the decline in Western industrialized societies, of those contexts for the performance of art music which had to do with religious observance, ritual, ceremony and celebration, as well as refined everyday entertainment and informed amateur music-making. With the idea of absolute music, a creation of the 19th century, there emerges a more and more exclusive focus on music as an object, in and for itself, of aesthetic contemplation. The musical experience becomes one of concentrated, solitary listening. If, through all this, attempts were periodically made to give new life to the religious and ritual contexts of musical performance (one thinks of Wagner's Parsifal or, in contemporary Canadian terms, of Murray Schafer's $R a$ ), this is only evidence of opposition to a prevailing trend.

While music becomes autonomous, the growing division and specialization of functions in musical production and reception serve to isolate composers, not only from listeners, but indeed from the by now complicated process that must mediate between conception, creation and realization. We are left, then, with a conflict, if not outright contradiction, between the reception context of intense listening, on the one hand, and, on the other, the mediating forces of material production and distribution which the composer now has difficulty controlling so that the meaning of what is to be listened to is communicated as originally conceived. Let me quote Murray Schafer on this point:

When a piece of mine is performed it is fairly certain that the conductor is doing it for the first time, the orchestra has never played it before, the audience has never heard it, and the program annotator knows nothing about it. From this adumbration of an event the critic is supposed to extract some vital truth for the national newspapers.

[Schafer 1984: 80] 
In order to understand the situation of which composers like Schafer complain we would have to look at some facts of contemporary musical life which may be well enough known but are too rarely laid open to critical scrutiny. What follows, for the purpose of discussion, are some tentative raids on the obvious.

One of the most important facts of today's musical life is that the production apparatus is fueled by economic power which has come to be concentrated in just a few hands far removed from any active engagement with music. Furthermore, this apparatus essentially serves what we may call, with Adorno, "official culture:" the symphony, opera and ballet organizations that preserve under glass the remnants of bourgeois ideology. This "culture," though somewhat protected from market forces by public funding (at least in Canada), is nevertheless too closely enmeshed with big business to be independent of the entertainment industry. The apparatus of marketed music is one that encroaches, too, on contemporary serious music, however much composers today may wish to see themselves as being free of it. The self-protective aura in which contemporary music concerts are typically wrapped does not mean that they are immune from forces operating in the world outside of them. Those who perform in such concerts are only rarely musicians who have developed attitudes to music-making different from those typical of the symphony hall or even the commercial studio. And those who mediate between the music and its public are the arts administrators and public relations officers of "culture" and its industry. Puzzled by the obscurantist language of program notes (admittedly written, at times, by the composers themselves), and looking in vain for informed music criticism in the daily press, the public sees only the hype which, like any other advertising, tells it that new is best.

Broadcasting media present problems of their own. If radio was for a long time important to music in this country, thanks to the $\mathrm{CBC}$, the significance of its role has more recently been diminished by the mindless chatter of serious music commentators, barely distinguishable from that of disc-jockeys. Too little is being done in the programming and presentation of radio to bring a piece of music to our attention as an event; too often we hear it as part of a kind of media jumble that reduces the sounds of all music to a generalized noise. Commercial radio makes no excuses for this: it deliberately exploits the principle of collage which makes all reflection impossible and reduces the listener to being merely a willing customer for the products it sells. 
In Canada we are torn between an enlightened policy which respects and nourishes different cultural identities, and a production and communications industry which is uncritical of itself and which drives us into homogenization. Canadian composers have certainly been sensitive to the threat of musical "grey-out," and many among them have sought to bring to their music elements drawn from their country's history and geography. Its folk traditions and unique ethnic and linguistic make-up. We hear, in their music, the Canada that has been neglected or violated: values relating to nature, the human community and also that individual, spontaneous behaviour which, at least for a while, redeems us from the social alienation typical of our contemporary world. But such values will fall short of being effectively realized if the material forces mediating between composer and listener cannot be bent to the purpose. Among such forces is the musical score itself, traditionally representing the autonomous work transmuted into an object for purchase, scrutiny and reproduction. Today's composers have attempted to subvert this objectification of what they do by allowing for accidents of performance to impinge on the composition, and by encouraging performers to avoid mechanical or conditioned responses in their recreation of the score. Such attempts to overturn the closed, autonomous work and replace it with something closer to music-making may collide, however, with market forces and those of media production, which tend to freeze human gestures and reduce them to commodities. Recordings are a case in point. Even recordings of contemporary music run the risk of alienating the listner when they are presented as authoritative embodiments, in themselves, of musical works. It is only too rarely that we, as listeners, are in a position to hear recordings as documents of performances to which alternatives are at least conceivable, if not actually available.

In the last decade there has been, in Canada, a significant decline in the level of state support for new music. The CBC is no longer especially active in commissioning and sponsoring performances of new works, and the Canada Council no longer funds the publication of new scores directly. Such developments are themselves only symptoms of a larger socio-cultural trend which is such as to raise more and more questions about the role of the composer as creator, the perceived instigator of a process which ends up with a musical performance. As his control over that process, with all its economic, technological and social ramifications, weakens, the composer may soon find himself - or herself - to be no more than an incidental figure in contemporary musical life. To become, once again, a true author, he would have to be able to 
depend on a production process that does not usurp him, but serves only as a means to the artistic end.

\section{John Beckwith}

One suggested recipe for fledgling composers today is: "Cultivate silence; then, locate interesting ways to interrupt that silence." The suggestion stems partly from a study of Mozart, where one is constantly struck by the frequent rests. But where does one find even relative quiet, let alone silence?

\section{Music as a Sound Message:}

It is getting harder and harder to achieve this. "Classical" is a sound, in the same sense as we use the term in the radio industry speaking of THE SOUND of a certain station, as in

a "contemporary" sound, meaning "m.o.r.,"

a "laid-back" or "c. and w." sound, or

a "beautiful music" sound.

Radio stations are not supposed to exist without a sound of some kind; more than 9 seconds of silence and you'll be logged by the management. But is the sound, or audio track, conveying a message, or merely providing a slick and homogenized background-environment that the dial-switcher can identify? Whatever the answer, "classical" has become one of the sounds around us, and its devotees make up a measurable part of the total consumership - four per cent is the latest estimate I say: it may now be less. "Classical contemporary," to use that self-contradictory but now generally-accepted term, is of course a small fraction of that four per cent.

A "classical sound" approach means everything from the tone of the announcer (soft, well-educated) to the background for the station-break promos: "Tune in tonight at 8 for Gustav Mahler's Fifth Symphony" is spoken against a recording of a tumultous ten-second thematic moment from the finale of that work, on which poor Mahler probably spent a solid two weeks of thought.

The "classical sound" is therefore in the same category of aural functionalism as the wailing female vocalist whose emotions I was unavoidably made conscious of on a visit the other day to my bank. The 
lady is no doubt talented and the insult to a recording which she devoted a good deal of skill to was just as real as the insult to Mahler; although she may have anticipated the insult and was surely well paid.

\section{Appropriateness}

In a talk I heard Carleton Sprague Smith give years ago he proposed a view of the musical repertoire that would divide it according to categories of appropriateness. What is appropriate for a baseball game may not be so for a funeral; what is appropriate for a symphonic concert may not be so in someone's living-room; what is appropriate in a bar may not be so in a church - although that last is an obsolete example, since church has become the one place any and every music is considered appropriate and permissible.

Format, length, scoring, level of difficulty, density, refinement - all of these features of a composition are influenced by appropriateness to the occasion or to the place or to the social group. I could give examples from my experience on request. So, yes, one does in that sense think in terms of message and hope for an effective transmission with one's hearers.

The notion of appropriateness reminds us that the large-concert-hall format is only one of many. It is a survival of 18 th-century middle-class liberalism, a temple of secular group-emotion that initially Joseph Haydn but also much later such composers as Berlioz and Wagner understood so splendidly. Haydn's London audiences of 1790 were eager for a message of uplift, of shared beauty. Familiar musical gestures and tune-progressions were developed as a serious and elevated argument of 20-to-30 minutes' duration; the essence of the experience was that it moved everyone in the group, literally shifted them from one mood to another or from one level of thought and feeling to another (probably to a deeper one).

Beethoven illustrated a generation later that the process could be made more riveting and sensational by repetition, rhythmic insistence, and (thereby) also an increased length of the argument -45 minutes instead of 30. Mahler also developed the idea of an added vocal element (from Wagner and Beethoven) and also thought of ways to achieve even greater weight and duration - a larger number of instruments, an exaperatedly slow tempo for the finale, and so on.

In the 1980s the big concert successes apply current technology to the same process - the concert pieces of Tredici on the one hand and Glass 
on the other are longer, louder, and higher-pitched than even Mahler, though the employment picture is not correspondingly improved: the amplification is by added electronics, not added performing personnel. Andrew Lloyd Webber says of his Requiem that by using a particular world-renowned tenor and a star soprano as soloists he increased the vocal range by an octave - I think he means over the range he himself used in his works for the musical-comedy stage, rather than the range used in the Alban Berg operas. But in his piece, as also in Tredici, the singers do stay in the upper fourth or so of their range for more of their time than required even with a character like Berg's Lulu; and they're overtly amplified (rather than secretly, as at the opera).

That may soon be the only kind of new pieces orchestra managements will risk putting on: they after all have to make an impact above the Brahms and Strauss on the rest of the concert, not to mention the canned "classical sound" in the boutiques out in the lobby at intermission (even in the concert-hall environment, quiet is not attainable any more, it seems). Perhaps the only successful alternative to longer, higher, and louder, is FUNNIER: if you can't stun everyone with an hour-and-a-half blockbuster of a cantata or symphony, try sending the conductor out onto the stage in a silly hat. At one moment the composer finds her/himself on a program alongside J.S. Bach, at the next alongside P.D.Q. Bach. One way or another, the packaging of concerts is hard for a genuine and listenable new composition to penetrate.

Of course, so-called coterie concerts and educational concerts largely avoid these problems. Let's hope they can continue their freedom to take risks: for composers, their existence is one hopeful sign in an unfriendly world. I don't refer to such circuits of small-scale events in any sense of snobbery or élitism. Just as with the small steady publics for early music or jazz, the genuineness of devotion, and warmth of interest, between professional and audience is in my view one of the really vital musical characteristics of our period. The sense of an interesting interruption of an established silence is certainly available in those circles. (In a Greenwich Village jazz club a couple of years ago I actually picked up a card on the table which read "Silence is requested during the performance." That was intelligent management; I noticed the request was well respected.)

\section{Durable music:}

This is a term suggested by Elliot Carter in one of his essays for a possible alternative for "classical" or "serious" or "concert" music. It 
represents a high hope on the creative artist's part: that his/her music will endure at least to a second or third performance even if it doesn't quite make it to "goldien-oldie" status. With this in mind, we custom-make our pieces with hand-tooled skills and refinements that we hope will stand up to repeated hearings, and will honorably maintain the highest composing standards of our tradition.

Just as Picasso measured himself against Delacroix and Hemingway against Dostoievski - both to their own disadvantage, by the way - so we also look at the great models of Bach and Beethoven and Chopin and Debussy even though realizing we can't achieve anything like their greatness.

However the reality is that our "durable music" is treated as a disposably commodity, more often than not. It is a product for which there is no expressed demand, and circumstances doom it to be ignored or half-heard much more often than listened to.

Is even a fine gripping work like Maxwell Davies' Third Symphony which I heard earlier this year more than a seasonal success? After its round of performances by leading orchestras will it also be treated as disposable in favour of whatever else comes along? Decent and "durable" pieces may receive four performances the first season and then one or two per season for another half-decade; and it's no comfort these days to find that the same fate has been shared by some fine pieces by Webern, Stravinsky, Hindemith - or perhaps by the early-80s achievements such as the Messiaen opera or the Davies Symphony. In one of his books Stravinsky remarks on the handful of live performances worldwide which Webern's Symphony Opus 21 had received in the (then) 30 years since it was composed. Would the same not be true of his own late works like Abraham and Isaac or the Movements for Piano and Orchestra?

Buzz-words:

40 years ago we were serial;

20 years ago, aleatoric;

10 years ago, minimal;

now we're again romantic.

Those composers who get their exercise by jumping on and off bandwagons are now suddenly unabashedly, lushly, romantic - 
something which would have struck us formerly as the worst, crudest, most unpardonable creative cop-out. Fortunately, we do live in a society where we can choose whether or not we want to ride the bandwagon.

\section{Why compose?}

The music world in general is hostile. There are far too many other composers. And the compromises can often be unpleasant - though usually this means compromises with the middlepersons rather than the audience. Why compose?

For me, it's what I seem to be gifted for; it keeps me out of mischief. Besides considerations of appropriateness in each new project, I'm reacting in a more general sense to inner compulsions which are identifiable as musical - the so-called "promptings of the muse." Boguslaw Schaffer says in his composition manual, "To serve one's society means to compose as well as possible." That makes sense.

\section{Alfred Fisher:}

To the composer, there are never enough people with a deep concern for contemporary music. The public's understanding of this concern is dim at best. In fact, the term "contemporary music" has almost drifted out of the North American vocabulary until its recent revival as a media code word meaning a corporately sculptured product created by someone called a "composer," very frequently, "artist" - normally a narrowly post-pubescent male who sings and strums into a "totally awesome Sony" ... the raw gravel then being refined to meet product need as determined by market research and the final product delivered by permanently post-pubescent types of the computer / waterbed / racquetball persuasion.

Even so, there is no reason why music - very good music written by "the other kind of composer" cannot be written in Edmonton, where I live and work. Some boosters of the city or of themselves feel that it has or, perhaps, even that it is being done. "The other kind of composer," after all, has access to pens and paper - and the environment is not so intense that he would not have unimpeded access to himself and to freedom from such environmental constraints that would prevent the composer from writing only and precisely the music that he wanted to hear. Of course, the burdens of the larger environment in which "the other kind of composer" is held, make it enormously difficult for composers anywhere to be personally, technically, intellectually and 
artistically so thoroughly self-consolidated and fearless as to be able to function with absolute independence ... but this is another problem and, I dare say, a much deeper one.

The more clearly observable problem of new music in Canada (if there is one), is located somewhere in the linkage between the composer and listener - assuming that there is linkage and not just space. Of course, in the more cohesive western musical culture of 200 years ago, the notion of linkage would have been largely irrelevant. Now, however, composers in Canada and the U.S. - with a few wonderful exceptions in both countries - do not, as a rule, perform. Performers do not compose and understand the programming of the music of "the other kind of composer" as a calculated risk that requires careful weighing of potential liabilities and benefits before offering it to a public that may be hostile and is ordinarily uncomfortable in dealing with experience that cannot be anticipated and assigned to some cateogry of convention for which the options for evaluation are preset.

There is, of course, a complex of factors that have coalesced to create this very regrettable condition - but there is one powerful strand that I wish to separate out and examine here . . . it is the one that you all are intimately if not tiresomely familiar with - but may not have related to new music, and the constellation of problems surrounding it. I speak here of the problem of education - or, more properly, the problem of the failure of education; bankruptcy and collapse at every level. I am not referring to specialized training in the arts here, but to "bedrock" matters ... reading, reflection, speculation - that failure which has led to the debasement of language and the betrayal of literature as a primary mode of intellectual and emotional engagement and growth that collpase which has led to the evaporation of critical independence and analytical thinking - of the withering of idea and the convenient substitution of information in its stead.

What has happened, in my view, is that the old line of an intrepid but misunderstood avant-garde and a diffident art-consuming public - (a colorful and productive old lie that no one has ever believed anyway) has - because of the peculiar social transmogrification in both constituencies, but referable to the same general collapse of education - been effortlessly adapted to a parallel but more inclusive pseudo-oppositional system. It is now a contest that features a champion - the media/government/education conglomerate - the new purveyors of culture, and a challenger - the target group of consumers who are massively indifferent but prepared to take the occasional "dive" - if only out of "respect." The shadow boxing in this ring is no longer 
between the electric and cunning lightweights of the avant-garde "peppering" the super heavies of the culture establishment... it is, rather, between the creation of liberal populism, the function of which is to suppport those activities that are assumed to legitimate us as a people capable of the same creativity and depth as past generations - and, the shapeless defenders of the new status quo - who are, of course, quite capable of telling us - in the same language as past generations...."I know what I like and I don't need to be told." This conglomerate, then, has appropriated for itself - or we have allowed it to appropriate for itself the role of progressive advocate - advocate of "good" ideas and - especially, advocate of "new ideas." However, it functions more often as the proponent of "non idea" while the brilliantly passive consumer is less often the defender of "received wisdom" and more often the defender of "no wisdom."

Let me tell you what all of this means for this "Canadian composer." It means that my audience, in view of its unwillingness or inability to approach music (mine or any other) with the objective of "knowing it," "using it," - even "loving it" - i.e., its unwillingness or inability to listen aggressively - welcoming challenge, attempting to penetrate in some way beneath the perception of music as merely a "sound object" ... it means that this audience, in view of what is to it the sheer strangeness of being forced into a situation demanding that parallels between new experience and old experience be searched out, will be "alienated" if only out of its unpreparedness to assume responsibility for comprehension. The composer, assuming that he himself is capable, can no longer assume that his audience is as well capable of this basic "act of mind" requiring the summoning forth of experience that has been the object of reflection, has been processed and internalized. Time and time again, the fact of such a disability and the bewilderment it yields has been made unambiguously, crushingly clear, even if, as so often happens - especially in a performance before a local audience - the apparent response is appreciative and enthusiastic. But because of traditional civility and because the audience has been sensitized by the culture machine to view contemporary music as an issue containing within it the narrower but perhaps more sensitive issue of Canadian music, a piece of mine appearing on a symphony program is likely to be the object of a highly artificial and ritualized form of respect ... respect not dissimilar to that accorded a special exhibit at the museum - one not nearly as exciting or rewarding as the permanent exhibits one experiences all the time.

It means that a performer of a work of mine, if it is not one of the few performance groups exclusively committed to new music, will have to 
overcome layers of resistance offered by musical/technical horizons determined by the "great repertoire" and by the surety that the audience associates the performers' talents with the music that confirms the unassailability of its own preferences.

The composer is not by any means a victim of the performer or the audience. There is no reason to romanticize his situation into the fantasy of the "rejected prophet." The same context has, of course, shaped his disabilities as surely as it has those of performer and audience. But, because the composer is the "originator" of the message that is passed through the performer to the audience, such disabilities, in that they deeply affect the way a composer thinks and hears, affect his expectations of his own work and of music generally, are inevitably exacerbated as they travel upward through the music consumption chain until they reach the carnivores at the top ... and here, of course, their effect will be grossly magnified. The paradox inherent in this strange circumstance is such that the music, quite independent of its real merit, will now usually be accepted without expressed complaint as "normative" (whatever that may be) by an audience that neither knows what to want or is too weakly engaged to risk the danger of wanting anything in particular.

Perhaps the "old saw" about the necessity of the composer to have "something to say" is a useful old lie as well, although I admit to you unapologetically that it is one in which I continue to find comfort. But it is difficult for composers maturing and writing within the described context to "get" that "something to say" - and if this something is not possessed, my experience as a teacher has made it clear that the void which stands in its stead will forever be unresponsive and unyielding to attempts to stimulate and enrich. Such a condition reduces involvement in music literature to absurdity and renders an "understanding" of musical materials quite sterile. The path to comprehension has become a litter of "information."

What I have described, then, is in fact a system in which something is made, delivered, consumed... and if my music were so many bags of potato chips, I suppose I might even find that satisfactory. But my music is the product of work and study... the product of search and some struggle and cannot be riveted into compatibility with any of the components of the system as I have described them. But, ladies and gnetlemen, stay your tears. Canada and North America is not yet barren of an audience that "knows" and "wants," nor of performers who "understand" and are "able," nor of composers who indeed do have something to "confess" beside the price of potato chips and the 
specifications on their new Fairlight. But this latter-day "League of David" is tiny for all its vitality, speaks mostly to itself and is, in the view of the monolith that surrounds it - reactionary, elitist and obscurantist. This little "cult" finds a supportive environment almost exclusively in universities. But the unfortunate intersection of educational collapse and an ascendant populist notion of universities and their purposes in this country has further restricted and isolated it while emboldening the culture consumers, happily burbling away in the belly of a whale, to feel perfectly secure in the absence of an acknowledged need to recognize the critical importance of making distinctions without which the idea of art makes little sense and has little value ... distinctions that separate significant from trivial, impetuosity from passion and calculation from intellection.

All of this, however, provides you with little insight with respect to the Canadianness of this composer. What I have described are the conditions within Canada that are perceived by a composer who happens to live and work in Canada. Such conditions are by no means exclusive to this country. And, though I have a real weakness for romantic nationalism, my music does not emerge out of rock and ice, out of bilingualism, the Stanley Cup, or the National Energy Policy. There is, however, a bottom level, a very personal level that is critical for me. It is the level at which my work encounters the Canada that stands behind the "trivial of human affairs." It has played a formative and synthesizing role in my life and work. Born in the U.S., I have for many years now been a Canadian citizen - a privileged Canadian citizen - privileged to have run wild rivers, slept under the midnight sun, and walked the Fundy Shore: I know absolute isolation, absolute silence, and what seems like unmeasurable distance. While such knowledge has not endowed me the gift with which one makes music out of the call of the loon, through "knowing" these things I have been strengthened to reach back to possess that which is neither Canadian nor American but mine - without diversification. Without compromise.

For this I am profoundly grateful.

\section{Barry Truax}

Unlike Western musicology with its focus on the score, ethnomusicology approaches music making from a functional perspective. In this context, it is useful to contrast the traditional Western concept of the composer which we have inherited with the functional context within which the contemporary composer operates. 
The Western concept of the composer as an individual charged with the personal creation of sound structures is a relatively recent development. This understanding divorces the composer from the performer. The composer's creativity is seen as the act of genius or special talent, something unteachable and irrational, removed from everyday life and actions, and hence the composer's works are self-expressing. The composer is seen as slightly removed from society, tolerated but shunned if he or she does not speak to society.

Combined with this concept of the artist as an individual is the concept of progress: in it the composer's actions are required to be not only original but innovative, modern not derivative. However, embedded within this mandate is the problem that the truly new is impossible to understand if it is based on rules that have no precedent. Gregory Bateson describes noise, in the sense of unpatterned information, as the only source of new patterns (Bateson 1972). The composer is therefore caught in the paradox that new musical sense, while reflecting a culture, may yet remain opaque (i.e."noise") to most of those within it. In Nicolas Slonimsky's formulation, "a modernistic monstrosity" in 20 years becomes "an artistic" curiosity and in another 20 years is elevated to a "modern masterpiece" (Slonimsky 1965:19).

For a while, it seemed as if the 20th century composer's response to this dilemma was to adopt the stance of iconoclasm. "Newer - and possibly uglier - than thou" and "I can break all the rules I want" were the adolescent responses of rebellion to a situation where the composer was deprived of power and subject to an extremely uncertain and brutal world.

The contemporary composer lives in an age where every aspect of the composer-to-audience process is constrained and influenced by at least two major forces, technology and the institutionalization of the arts. The latter has resulted in the arts adopting an industrial/commercial model by which to function. But whether a composer is "commercial" or not, he or she is irrevocably affected by commercial forces within the society. By not being commercial, the arts must be protected by government intervention and thereby become polarized with respect to commerce. Through the lack of access to the mass media, there is an inevitable "ghettoization" of the arts - they become "programmed" for failure and marginality.

Whether we like it or not, we are all affected by commoditization, the mass market, and the "economic realities" of artistic life. We do not have creation, patronage and appreciation of the arts (although we like 
to think we do), but rather their production, funding and consumption. We are therefore forced to operated under an industrial model but without access to the means of distribution that would make our endeavours "profitable."

The result is that composers cannot support themselves solely through the practice of their craft; their principal livelihood must be found in other professions. Statistics show that the majority of artists' incomes from professional activities fall beneath the poverty level. In effect, the arts in Canada are being subsidized by the artist's own labour.

A consequence of this "production" mentality is that only new works, like new products, are regarded as important and therefore funded, recorded, etc. But as in the industry, newness means novelty and not inherent originality. The mass market requirement - as opposed to that of the public - dictates that what sells is only what appears to be new. Anything really original would require change and thought. Instead, different styles in art become analogous with different brands of a similar product. Other consequences of the industrial mentality are a dependence on the cost-effectiveness of performances - i.e. what is affordable to produce - , on quantity - commissions and performance royalties are paid by the minute -, and on reproduction mass-produced copies versus originals.

The change is from patronage to funding policy. Culture is now seen as a political responsibility and issue, and artists are treated as "cultural workers" in the "cultural industries." In Canada, regional balance is one of the many extra-musical factors in cultural policy; quality decisions are often in conflict with funding priorities and economic viability.

Consumption criteria, such as audience size and target audience appeal, seem to be considerations reflected in a recent trend within the $\mathrm{CBC}$ to move away from serious and specifically Canadian culture. Futhermore, the lack of professional criticism, particularly in the press, acts as an indirect censorship of contemporary music by the entertainment editors who prevent reviews presumably because they fear losing readership. An increasing use of "previews" in their place means that the arts are treated along the lines of the advertising model. "Consumer reports" for the arts are thus lacking, and there is little public feedback.

The influence of technology today is felt on all aspects of the process of music distribution and consumption even if the composer is not directly involved in technologically produced music. However, there is surprisingly little interest or support for electroacoustic music within the 
music establishment, compared to the pervasiveness of technological influence.

In fact, the audience's experience and listening habits are probably influenced more by electroacoustically (re)produced sound than by live acoustic experience. With distracted listening, background music, repetition and brand loyalty, the focus is more on the consumption of music rather than its production. The listener has become a consumer of audio products and services, which means that sound now has exchange value and not just use value. This has also radically affected the means of distribution of music. More people can now hear a given work in a single broadcast or recording than in countless live performances. The ultimate destination or context of the musical message, however, is unforeseen by the composer.

Electroacoustic music is often treated as second class by the artistic establishments. Yet more and more of the music that is heard is electronically produced. Indeed, one attraction of technology is that it is a source of the power that is denied the contemporary composer; in terms of power, the orchestra and chorus of the 19th century may be seen as comparable to the powerful synthesizer today. Given that the former is virtually unavailable as a performance possibility, the contemporary composer must be content with the latter.

Technology thus plays a dual role - it extends our capabilities and constrains them within the consumer marketplace. It is tempting to characterize technology as a "zero sum game" because for every advance there appears to be a corresponding disadvantage. With the proliferation of technological change it is difficult to assess that balance and to distinguish what is truly new from the what only appears new. We are left wondering whether any real net gain is the result, or if every advance simply has its price.

From a communicational perspective, I have argued (Truax 1984) that the net extension of technology occurs from what changes the process, not just the content of communication, from what makes us understand ourselves and the world differently, not from what repackages the past in new guises. In terms of composition, the extensions of technology are the new ways in which the organization of sound material, the compositional structure and the communicational environment can be designed. In short, technology is allowing us to design the compositional process and therefore to think differently through sound. But that is the challenge: it allows, it doesn't require that change in thinking. Too often, our own mindsets, as well as institutional and commercial forces, 
protect us from the potential for change and the truly creative that technology offers.

Interestingly enough, the current trend in computer music foretells, if I am reading the signs correctly, the reintegration of the performer/composer split of the last two centuries. In the first instance, it already requires the studio composer to become the performer of each stage of work on tape as it is assembled and thereby forges a more direct link to the audience. But as technology becomes more powerful it also allows more of what a studio composer does in isolation in the studio to be done live in performance. The fact that more of this power is affordable today by the individual heralds a trend towards decentralization and widespread experimentation, provided the individual embraces the potential that the technology allows. Attali sees this de-systemization in musicmaking as presaging an economic model that will challenge the dominance of corporate empires bent on the stockpiling of semi-identical products (Attali 1985). The future of the composer-to-audience pathway may well depend on how we use this technology.

\section{Insights and Issues}

The four presentations extend both awareness and eloquence across the entire spectrum of forces and factors involved in the production process of music and its inevitable enmeshing with contemporary socio-political and economic forces. This includes reflection on the place and purpose of the composer within the context of the Canadian polity and the university as his prime locus operandi. What strikes throughout all four exposés is a pervasive sense of pessimism, of something intrinsically wrong with the music-making process itself, embedded, as it is today, within a market economy whose powerful forces can be countered only by governmental intervention, leaving little individual autonomy. This is nothing new; what is of interest here is to identify this malaise in its particular features as the composer sees it, so that it may serve as a source for clarifying his - or her - musical role in that process. In order to build such a composite profile of the composer's vantage point from the foregoing, I propose to proceed topically by focussing on each link in the chain of music production, starting with the audience and ending with the composer himself.

The composer's audience is in a general sense synonymous with the public, although he recognizes special listening groups. Considered a distant entity, lacking autonomy, the audience at large is seen as a 
consumer of a vast "collage" of different kinds of music. It is subject to manipulation by market forces, and also by technological processes of sound reproduction. While it accepts the composer as a music-cultural or even a national "institution", it is fundamentally indifferent to his message, lacking either concern or capacity for apprehending it. The composer in turn expresses alienation and thus returns this indifference, mingled with some degree of hostility. ${ }^{2}$ Within the listening public at large, the support of special audiences are acknowledged, but the composer clearly aims at a broader target. The primary context of performance is the classical concert, as the traditional locus for the composer's unique, yet appropriate contribution to the "elevated argument" and its emotional impact which continues to emanate from the long line of his illustrious predecessors. Whether taken for granted or considered a burden, the constraints of tradition are clearly felt, along with a desire for performance contexts appropriate to the contemporary composer in his own right, especially the composer of electro-acoustic music.

Perhaps of equal de facto importance as a means for the composer's communicating with audiences is the medium of sound reproduction, most of all radio, the locus of musical pluralism, where the musical utterance needs first and foremost to assert its identity vis-a-vis the broader contemporary soundscape. It is here that the composer feels overpowered by the market as a determinant from which he sees himself excluded.

Performers, who after all mediate between the composer's score and the audience, receive the least attention in the composer's consideration of the music production process, perhaps because they are seen as lacking autonomy, being subject to the same larger forces as composer and audience, or because their engagement is with the traditional classical repertoire from which they derive their professional legitimacy. Eliminating the intermediary is the solution of the studio composer, thus enabling him to address the audience directly. Altogether, the marginal place allotted to the performer in our presentations appears symptomatic not of the composer's actions - for he obviously does interact with performers - but rather of his ideation in which his own artistic autonomy is of primary concern.

2 In flavour, if not its socio-economic basis, the sentiment has strong European antecedents, dating back to Wagner. 
In the composers' view the most crucial facet of the contemporary "serious" music production process is patronage and funding, the very determinants of its existence in Canada. The picture suggested here is one of anonymity and centralisation, characterized by the absence of personal patrons and the influence of market norms of novelty and disposability. An overwhelming force, this patronage is nevertheless considered inadequate, as to both extent and artistic criteria. Due to a lack of alternatives a per force dependence on public funding creates a sense of ghettoization as well as paralysis, all components of a strongly felt problematic in the exposés under discussion.

In the light of all this, the composer appears to see himself and his idiom in the throes of some fundamental contradictions. $\mathrm{He}$ - or she - is the inheritor of a model of the past, but is expected to distinguish himself within it as a protagonist of the present. He is society's creative voice through music, but society hardly demands to hear him. He is expected to say something new, distinct from the musical past, but his idiom must nevertheless sound "classical". He says something new, but finds audiences unwilling to decipher his idiom. He addresses himself to the public that is his audience, but finds himself separated from his listeners by a complex process of production. He must be of relevant to today's society, but the use of this society's most powerful tool, technology, generally eludes him. He embraces electro-acoustic technology but risks alienating his own artistic establishment.

Divergent responses are evoked by these contradictions. Underlying their variety appears to be a sense of societal loss - loss of relevance and, linked with it, loss of control, most immediately pertaining to the process of music production. No less pervasive is an underlying sense of commitment to the composer's role as a true "author" and of his utterance as a substantive contribution to society.

A concomitant twinning of integrity with isolation characterises the composer's stance of artistic individuality, whatever its particular type or flavour. Whether this stance can generate the creative impetus needed for a new kind of participation in the dynamic of the music making process is a question crucial not only to the composer but to the well-being of "serious" music itself. 


\section{REFERENCES}

ATTALI, JACQUES.

1985: Noise: The Political Economy of Music, Minneapolis: University of Minnesota.

BATESON, GREGORY.

1972: Steps to An Ecology of Mind. New York: Ballantine.

QURESHI, REGULA BURCKHARDT.

1987: "Musical Sound and Contextual Input: A Performance Model for Music Analysis," Ethnomusicology 31(1): 56-87.

SCHAFER, MURRAY.

1984: On Canadian Music. Bancroft, Ontario: Arcana Editions.

SLONIMSKY, NICHOLAS.

1965: Lexicon of Musical Invective. 2nd ed., Seattle: University of Washington Press.

TRUAX, BARRY.

1984: Acoustic Communication. Norwood, New Jersey: Ablex Publishing. 